\title{
Dependence of Life Expectancy of the Population on the Well-Being of the Country (International Statistical Study)
}

\author{
V. K. Fal'tsman* \\ Institute of Applied Economic Research, Russian Academy of National Economy and Public Administration under the President \\ of the Russian Federation, Moscow, 119571 Russia \\ *e-mail:m975032@gmail.com
}

Received October 12, 2020; revised October 26, 2020; accepted November 17, 2020

\begin{abstract}
The article examines the results of processing statistical data for 180 countries of the world, on the basis of which a welfare scale is built, which characterizes the increase in life expectancy of the population as GDP (PPP) and healthcare costs grow. The scale is used to predict the life expectancy of the Russian population.
\end{abstract}

Keywords: well-being of the population, life expectancy, the scale of the well-being of the countries of the world, healthcare costs

DOI: $10.1134 / \mathrm{S} 1075700721020052$

The study of the influence of the level of economic development on the life expectancy of the population is one of the most pressing topics of interdisciplinary research of economists, demographers, and physicians. For a review of recent studies related to life expectancy growth factors, see the HSE publication [1]. The fundamental works in this area are the publications of Arrow [2] and Aganbegyan [3].

The relevance of this topic has increased due to the rapid cross-border spread of the COVID-19 pandemic. As a result of the study, we come to the conclusion that the colossal gap in the level of welfare of countries not only reduces life expectancy in the developing world, but also affects developed countries. The humanitarian mission of the international community to assist the development of lagging countries fully meets the interests of the developed countries that are its sponsors. The international community must create conditions for increasing the level of development of lagging countries, in particular, remove restrictions on the distribution of intellectual property products and sanctions on the development of international trade. The world community is interested in increasing the effectiveness of foreign aid to underdeveloped countries [4].

Welfare scale construction methodology. The article uses a system of three interrelated indicators: life expectancy (LE) $(y)$, GDP (PPP) per capita $\left(x_{1}\right)$, costs of health care development, in US dollars $\left(x_{2}\right)$. The wording of the content of the indicators is given below in the edition of the database developers and the Federal State Statistics Service of the Russian Federation. The essence of the study is to build numerical models
$y=F\left(x_{1}\right)$ and $y=F\left(x_{2}\right)$ and their verification in relation to the Russian economy.

The health of the nation and the well-being of the population of the country is characterized by the LE indicator. More precisely, it is called life expectancy at birth (life expectancy) and is measured by the number of years that a person from the birth generation would have to live on average, provided that throughout the life of this generation, the age-specific mortality remains at the level of the year for which it was calculated. (In what follows, for brevity, we will use the abbreviation LE).

The economic factors that form life expectancy are health indicators, availability of work, food quality, housing conditions, the state of the natural environment, education, personal safety and other aspects of human life. As a result, it can be stated that the life expectancy indicator is integral to assess the quality/well-being of life [5].

During the pandemic, it became obvious that the level of the country's GDP cannot accurately reflect the level of well-being of the population [6]. This indicator does not tell us anything about whether we have a job, a home in a safe place surrounded by a clean, nontoxic natural environment, access to quality health care, healthy food and other benefits of life [7]. Therefore, for cross-country comparisons, in addition to GDP, the LE indicators and the level of healthcare costs were used, which characterize the quality/wellbeing of the population.

The work used a databank of the LE indicator for 2016 for 180 countries of the world, developed by the 
Table 1. World wealth scale

\begin{tabular}{c|c|c|c}
\hline $\begin{array}{c}\text { Sequential numbering } \\
\text { of a group of countries }\end{array}$ & $\begin{array}{c}\text { GDP (PPP), } \\
\text { thousand USD/person }\end{array}$ & $\begin{array}{c}\text { Healthcare costs, } \\
\text { USD/person }\end{array}$ & Life expectancy, years \\
\hline 1 & 1.3 & 35 & 60.5 \\
2 & 2.0 & 62 & 64.0 \\
3 & 2.7 & 52 & 61.9 \\
4 & 3.6 & 180 & 65.4 \\
5 & 4.5 & 122 & 66.3 \\
6 & 6.3 & 131 & 69.4 \\
7 & 8.3 & 178 & 70.8 \\
8 & 10.1 & 399 & 72.1 \\
9 & 12.6 & 237 & 73.0 \\
10 & 14.8 & 560 & 74.2 \\
11 & 16.9 & 459 & 72.7 \\
12 & 19.7 & 564 & 73.5 \\
13 & 25.8 & 716 & 76.0 \\
14 & 30.6 & 917 & 76.0 \\
15 & 36.9 & 1846 & 79.4 \\
16 & 45.7 & 3214 & 81.8 \\
17 & 54.0 & 3991 & 80.8 \\
18 & 83.3 & 4550 & 79.7 \\
Average & 21.1 & 1012 & 72.1 \\
\hline
\end{tabular}

WHO (World Health Organization) ${ }^{1}$. To characterize the well-being/quality of life in countries, the GDP per capita indicator was used, measured in thousands of dollars US using purchasing power parity (PPP). PPP is the ratio of prices for groups of goods in national currency and in dollars. It is used to convert the GDP indicator in national currency into USD and allows for international comparisons of the level of economic development/prosperity of the states of the world, excluding the factor of inflation of national currencies.

A PPP GDP data bank was compiled by the IMF for 2018.

The cost of LE maintaining is only a fraction of GDP. For example, spending on defense, on the implementation of infrastructure megaprojects at the current level of life expectancy is not reflected. At the same time, along with GDP at PPP, for comparative analysis, the indicator of healthcare costs was used, which directly forms the indicator of life expectancy, influencing the reduction of morbidity and mortality of the population. Any costs are not identical to the results. Therefore, it is necessary to additionally touch upon the problems of health care efficiency.

A data bank on the indicator of expenditures on health development (in US dollars) was created by the WHO in 2015.

\footnotetext{
${ }^{1}$ Latest WHO publication at the time of writing.
}

Each country has a specific set of factors that shape the life expectancy of the population under the influence of GDP growth at PPP. Since we are interested in the general pattern, the method of average values was used to identify it.

The list of 180 countries was ranked by increasing per capita GDP by PPP and divided into 18 groups. Each group included 10 countries with relatively similar GDP values. Moreover, each subsequent group of countries has a higher welfare than the previous one.

The calculated average values of GDP per capita PPP, life expectancy and healthcare costs for each group of countries (the scale of welfare of countries of the world) are presented in Table 1.

Analysis of the scale of welfare of the countries of the world leads to the following results. In the world economy, a colossal gap has formed between countries in the quality of life, the level of the welfare indicator of GDP based on PPP and, accordingly, in LE. The range of change in the well-being indicator is in the range from 1.3 to 83.3 thousand dollars per one inhabitant of the country. The uneven economic development of the countries of the world has a detrimental effect on the life expectancy of their population. With an average life expectancy for all countries of the world equal to 72.1 years, the value of this indicator varies from about 60 years for the poorest countries to more than 80 years in the richest countries. Poverty in underdeveloped countries affects the premature mor- 
tality of older people and, at the same time, the high birth rate of children who are not provided with the means for a normal existence.

The higher the economic well-being of a country, the more is spent on health care. This pattern is violated if the country has to rearm, carry out costly megaprojects with long payback periods, eliminate the consequences of man-made and natural disasters, epidemics, military conflicts, provide significant international assistance to allies in political blocs, issue illconceived international loans without proper security, spend funds in any other areas not related to improving the quality of life of the population.

A very close relationship between GDP at PPP of countries $\left(x_{1}\right)$, their health care costs $\left(x_{2}\right)$ and life expectancy $(y)$. Pairwise correlation coefficient calculations $(R)$, made according to Table 1 , confirmed the hypothesis of the statistical significance of the closeness of the relationship between these indicators:

$$
R\left(y, x_{1}\right)=0.82 \text { and } R\left(y, x_{2}\right)=0.76 \text {. }
$$

As expected, the close relationship between life expectancy and GDP based on PPP turned out to be higher than with health care costs, since the first of these two independent variables more fully reflects the whole range of factors that form life expectancy.

In all 180 countries, life expectancy for men is less than for women. Isn't this fact evidence of the secondary nature of national characteristics and differences between countries and peoples in relation to the unity of the Homo sapiens population?

The LE indicator can be proposed as a new criterion for classifying countries. In accordance with this criterion, countries with LE from 60 to 69 years can be classified as underdeveloped countries (the first 60 countries, from 1st to 6th group). We call this aggregate conditionally " 60 -years-old." Developing countries include countries with life expectancy in the interval from 70 to 80 years. The seventy-year-olds include country groups from the 7 th to 14 th. The developed countries include countries with life expectancy of 80 years or more. These are the countries of long-livers. In Table 1, these include groups 15 to 18 .

The life expectancy criterion more accurately reflects the differences in the quality/well-being of countries in comparison with the GDP indicator (PPP). For example, according to our classification, health care costs in underdeveloped countries average 90 USD/person, while in developed countries they reach 3400 USD.

US LE deserves special analysis. In this country, it is 78.5 years. According to this indicator, the United States loses to other countries from the group of centenarians, although healthcare costs are the highest here at 9.5 thousand USD/person. It remains unclear whether the life expectancy of the US population is affected by high migration from less prosperous countries; how high US exports of medical services affect LE.
The regularity is confirmed: as the economic wellbeing of countries increases, the life expectancy of the population increases. This means that the dynamics of the life expectancy of the population of the country within certain limits can be "controlled" by the state. From the data on the welfare scale, it follows that at the current level of the state of medicine, the upper limit of the average life expectancy for all countries is approximately at the level of 80-82 years. By the way, 70 and 80 years were named as the limits of human life span in the Gospel 2000 years ago.

Measurements of elasticity showed that life expectancy, like other demographic indicators, has a high inertia, weakly responds to the influence of factors that form it, which are more dynamic in nature.

In the context of the homogeneity of the classification of the groups, the countries of the Middle East that produce and export oil should be distinguished. This group includes Saudi Arabia, UAE, Qatar, Brunei, Bahrain, Kuwait, Oman. These wealthy countries are ranked in the 17th and 18th groups of the richest countries in the world in terms of wealth. The average GDP (PPP) of these countries is about 71 thousand USD per capita; per capita GDP (PPP) exceeds most countries in Europe and the United States. However, the life expectancy in these countries is noticeably lower than the European average. For example, in Saudi Arabia and Kuwait the figure is 75 years.

It should be noted that health care expenditures in this group of countries are much lower than the European average (1200 USD/person). But this circumstance can hardly affect life expectancy: the rich population of these countries has free access to high-quality Israeli and any other foreign medicine. In addition, the population of these countries is much younger than the European one and therefore requires objectively less expenditures on maintaining health.

The ethnic composition of the population has little effect on life expectancy. For example, this indicator in the Republic of Korea is 82.7 years, and in the DPRK, 71.5 years. In the Democratic Republic of the Congo (formerly Zaire), the LE is 64.5 years, and in the Republic of the Congo it is 60.5 years. Singapore has the third largest GDP (PPP) per capita in the world. Health care expenditures in this country exceed 6000 USD per year, life expectancy is 82.9 years. The ethnic composition of the population of this country consists of three quarters Chinese, so it is appropriate to compare these indicators with the PRC, where health care costs are almost three times less, and the life expectancy is 76 years.

Western Europe is usually considered the standard for improving the quality and life expectancy (Table 2). At the same time, a necessary condition for the convergence of the country's indicators with their reference value is its economic growth.

The highest health care costs in Europe and worldwide are in Switzerland. They amount to an average of 
Table 2. Health and Life Expectancy in Western Europe

\begin{tabular}{c|l|c|c}
\hline Rating by GDP (PPP) & \multicolumn{1}{|c|}{ Country } & Costs for healthcare, USD/person & Life expectancy, years \\
\hline 2 & Luxembourg & 6236 & 82.4 \\
4 & Ireland & 4757 & 81.5 \\
6 & Norway & 7464 & 82.5 \\
9 & Switzerland & 9818 & 83.3 \\
12 & Netherlands & 4746 & 81.6 \\
13 & Iceland & 4375 & 82.4 \\
15 & Sweden & 5600 & 82.4 \\
16 & Germany & 4592 & 81.0 \\
18 & Denmark & 5497 & 81.2 \\
19 & Austria & 4934 & 81.9 \\
Average & & 5802 & 81.7 \\
Peace (UN) & & 1000 & 67.2 \\
\hline
\end{tabular}

9800 USD per year per inhabitant. Accordingly, life expectancy in Switzerland is higher than in the rest of Europe at 83.3 years. People in this country live 16 years longer than our average contemporary in the world (67.2 years). Of all European countries, Iceland has the lowest health care costs at 4700 USD per year per inhabitant. This is about a quarter less than the average European level (5800 USD per person). But at the same time, life expectancy in Iceland is 82.4 years, which is above the European average ( 81.7 years).

Russia's place on the welfare scale. In the context of cross-country comparisons, Russia's place on the scale of welfare is determined by the following facts: per capita GDP (PPP) indicator is 50th in the world; healthcare spending, 69th place; LE, 103rd place in the world. The ratio of these ratings hides the priorities of social and economic policy.

In terms of healthcare costs, Russia is inferior to the rest of the world by as much as 19 rating points. In the WHO ranking of health care costs, Russia follows Mexico and Ecuador and precedes Mauritius ${ }^{2}$, although in terms of GDP per capita PPP, it is significantly ahead of them. The reason is that in the priorities of socioeconomic policy, healthcare in our country for many years has been in more modest positions than in other countries.

Using the available data bank for individual countries, we will calculate the share of per capita health expenditures for Russia, which, according to WHO statistics, is 524 USD per capita per year. In the country's GDP at PPP (29000 USD/person), it is $1.8 \%$. Even in underdeveloped countries, the share of healthcare is higher than in Russia: on the scale of welfare (see Table 1) in the groups of underdeveloped

\footnotetext{
2 The official statistics of the Ministry of Healthcare of the Russian Federation may differ from the UN statistics that are used in this study as the initial database.
}

countries, it varies from 1.9 to $3.1 \%$, in the countries of reference welfare it is twice as high, it reaches 5-7\%.

In the wake of the pandemic, many countries will increase health spending. There is no doubt that Russia will be among them.

If Russia were able to increase the share of spending on healthcare to 5\% (the minimum level for developed countries), then even with a constant value of GDP at PPP, spending on health care would rise to 1450 USD/person. Greece and Cyprus currently spend about this amount on healthcare.

It will be possible to overcome the lag of the world ranking of Russia in terms of health care costs from the rating of GDP (PPP) per capita if the priority of health care in the country's economic and social policy increases, and spending on medicine, considered as the most important criterion of the quality of life of the population, is increased. In modern studies of the mortality rate of the population, well-known demographers state that, despite the implementation of a number of regional programs of Russia on technological reform of healthcare, the lag of Russian megacities from foreign ones in reducing mortality from cardiovascular diseases (occupying the first place in the structure of causes of death) remains very significant. At the same time, it is noted that this is "probably due to insufficient financing of Russian healthcare” [8, p. 154].

Next, it is necessary to analyze the reasons why the international rating of life expectancy in Russia (103rd place in the world) significantly lags behind the ranking in terms of healthcare costs (69th place). Objective reasons that reduce the efficiency of healthcare costs in Russia are:

-Huge territories, which in the conditions of the Russian off-road and the practical loss of small aircraft make it difficult for the population to access medical services. 
- Significant threats to life due to high alcohol consumption, insufficient road safety, man-made accidents and disasters in heavy industry and transport.

- Lag in the quality of healthcare services, in the provision of modern medical equipment, drugs, and most importantly, in the qualifications of doctors and nurses.

-Overcoming the harmful consequences of "optimization of medical care," as a result of which a huge number of small regional hospitals and medical assistant posts, almost 100 thousand hospital beds were eliminated [3, p. 320].

For these reasons, one US dollar invested in healthcare in a European country and in Russia has a different effect. In our country, the return on healthcare costs is less. Life expectancy in Russia is 71.9 years. It is significantly lower in comparison with countries that, in terms of GDP (PPP), are included with us in the 14 th group of countries on the welfare scale. For example, in Latvia, the life expectancy rate is 75 years, in Malaysia 75.3 years, in Hungary 76 years, in Poland 77.8 years, and in Portugal 81.5 years.

Russia needs massive health care reform. Thanks to the creation in recent years of dozens of major medical centers for the provision of high-tech care, equipping them with tomographs, ambulances, nuclear and telecommunications medicine, and medicines based on import substitution, Russian healthcare has turned out to be better prepared to fight the pandemic than could be expected.

Conclusions. In order to improve the quality of life and its duration from 71.9 to 80 years by 2030 , Russia will need ${ }^{3}$ :

-To move from the 14th to the 15th step of the scale of welfare, for which it is necessary to increase the GDP (PPP) per capita by $20 \%$ and approximately double the cost of healthcare.

-To improve the quality of medical services by completing the modernization of healthcare, equipping it with the latest technologies, medicines and new equipment.

\footnotetext{
${ }^{3}$ It took Russia 15 years to increase life expectancy by 7 years (2001-2016). According to the Russian Federal State Statistics Service, life expectancy in Russia was 72.91 years in 2018.
}

-To train the medical staff of a new generation of Russian doctors (the most difficult), which will require at least a decade of hard work. It is interesting to refer here to the experience of training doctors in Western Europe and the United States, which is described in great detail in [3].

Attention should be paid to one alarming circumstance: the international rating of the well-being of the Russian economy (GDP at PPP per capita) is significantly higher than the indicator of quality of life - life expectancy. To live longer, the population of Russia needs an unconditional priority in the development of healthcare and a healthy lifestyle. In the hierarchy of target macroeconomic indicators, it is necessary to raise the priority of life expectancy and healthcare costs to at least the GDP rating.

\section{CONFLICT OF INTEREST}

The authors declare that they have no conflicts of interest.

\section{REFERENCES}

1. M. G. Kolosnitsina, G. V. Kossova, and M. A. Sheluntsova, "Life expectancy growth factors: Cluster analysis across the world," Demogr. Oboz. 6 (1), 124-150 (2019).

2. Kenneth Y. Arrow, "Unceratainty and the welfare economics of medical care," Am. Econ. Rev. 53, 941-973 (1963).

3. A. G. Aganbegyan, On Priorities of Social Policy (ID "Delo," RANKhiGS, Moscow, 2018) [in Russian].

4. V. K. Fal'tsman, "On international assistance to the poorest countries," Mirovaya Ekon. Mezhdunar. Otnosheniya 64 (8), 56-62 (2020).

5. V. K. Fal'tsman, Problems of Russia's Economy until 2050: Monograph (MAKS Press, Moscow, 2020) [in Russian].

6. O. A. Kislitsyna, Measuring the Quality of Life and WellBeing: International Experience (Inst. Ekon. Ross. Akad. Nauk, Moscow, 2016) [in Russian].

7. Canadian Index of Wellbeing. How Are Canadians Really Doing? (Univ. Waterloo, 2011). https://uwaterloo.ca/canadian-index-wellbeing/.

8. T. L. Kharkova, E. A. Kvasha, and B. A. Revich, "Comparative assessment of mortality rate of the population in Russian and foreign megacities," Stud. Russ. Econ. Dev. 29, 690-697 (2018). 